\title{
EL USO CORRECTO DEL CORREO ELECTRONICO
}

\section{THE CORRECT USE OF EMAIL}

\section{AUTORES}

Julio Gutiérrez: Departamento de Física. Universidad de Alcalá de Henares.

julio.gutierrez@aol.com

\section{CURRÍCULUM VITAE}

Catedrático de Física Atómica, Molecular y Nuclear en la Universidad de Alcalá de Henares. Autor de varios libros de distinta temática

\section{RESUMEN}

Siguiendo con nuestra idea de dar a nuestros lectores una serie de pautas que les permitan navegar adecuadamente por Internet y usar correctamente el correo electrónico, hemos recopilado un conjunto de normas de utilización del correo electrónico en general, que si bien no son obligatorias, salvo en algunas listas de distribución muy particulares, si son de gran utilidad porque nos permiten evitar malos entendidos.

\section{PALABRAS CLAVE}

Correo electrónico - Correspondencia - Normas - Internet - Navegar

\section{ABSTRACT}


Following our idea to give our readers a series of guidelines that enable them properly navigate the Internet and use email properly, we have compiled a set of rules for use of email in general, although not mandatory, except in some very specific mailing lists, if they are useful because they allow us to avoid misunderstandings.

\section{KEY WORDS}

Email - Mail - Standards - Internet - Browse

\section{ÍNDICE}

1. No debemos olvidar que en el otro extremo hay también una persona.

2. Brevedad.

3. Los mensajes electrónicos son un reflejo de quién los escribe.

4. Cómo contestar a un mensaje.

5. Participación en grupos de discusión, debate e información.

6. Envío de archivos adjuntos.

7. Publicidad.

8. Se deben usar títulos descriptivos para los mensajes.

9. Cuidado con el humor y sarcasmo en los mensajes electrónicos.

10. Se debe hacer partícipes a los demás de los hallazgos.

11. Sobre la apropiación de ideas.

12. Sobre la privacidad.

13. Firmas.

14. Uso de siglas.

15. Criterios de cientificidad en las listas de distribución.

16. El correo no solicitado.

17. El problema del SPAM. 
18. El problema de los mensajes BOMBA.

19. Difusión de contenido inadecuado.

20. Difusión a través de canales no autorizados.

21. Recomedación final.

\section{No debemos olvidar que el otro extremo hay también una persona.}

Cuando escribimos una carta en papel, aunque sea una circular, solemos visualizar a una persona leyendo el texto $\mathrm{y}$, por eso, somos extremadamente cuidadosos. El ordenador nos ha convertido en más fríos e impersonales y es fácil olvidar que hay personas al otro lado de la red. Si nuestros mensajes son habitualmente agresivos o demasiado "pedigüeños", posiblemente seremos menos ayudados cuando lo necesitemos. Si por cualquier motivo estamos alterados lo más conveniente será esperar un poco antes de contestar a un mensaje que nos ha sacado de nuestras casillas o enviar uno nuevo donde dejemos constancia de nuestro estado de ánimo.

Hemos de tener en cuenta las personas a las que se está enviando el mensaje.

Si lo que queremos es hacer una prueba y comprobar si un mensaje alcanza su destino, se pondrá en la línea "subject:" esto es una prueba . Se intentará no enviar pruebas a una lista de distribución.

\section{Brevedad.}

Las frases breves tendrán mas impacto que los largos párrafos, lo cuales, probablemente serán menos leídos. Por otra parte, la pantalla, en la mayoría de los casos pequeña, no permite hacer una lectura rápida para entresacar el contenido del texto. Además, tampoco estamos lo suficientemente habituados como para leer grandes cartas en el ordenador. Algunos usuarios todavía sacan los mensajes por 
impresora previamente a su lectura. Quizás en las generaciones futuras estas dificultades desaparezcan, pero en estos momentos conviven dos tipos de cultura que debemos respetar.

Recuerde que las direcciones de correo que se incluyan en el campo "Para:" o en el campo "Con copia:" forman parte del mensaje que usted envía. Si el número de destinatarios es elevado el método aconsejable es incluirlas en el campo "Con copia oculta:" (en inglés, "Blind Carbon Copy:").

\section{Los mensajes electrónicos son un reflejo de quién los escribe.}

Muchas de las personas que, a través de la red, reciben nuestros mensajes nos conocerán por lo que escribamos y cómo lo hagamos. Tengamos cuidado con el contenido y ortografía de lo escrito para que más tarde eso no sea motivo de vergüenza.

\section{Cómo contestar a un mensaje.}

Antes de contestar un mensaje recibido, bien en línea directa o a través de una Lista de discusión, debate o información, se deben tener en cuenta los siguientes puntos:

- La cita completa del mensaje anterior que está respondiendo es totalmente innecesaria, ya que ha sido escrito por el remitente o recibido por el resto de miembros de la lista. y no aporta nueva información. Hay que tener en cuenta que casi todos los programas que gestionan correo electrónico colocan, como opción por defecto, cuando se elige la posibilidad de responder al remitente, la copia íntegra del mensaje recibido. Se puede cambiar esta opción - es nuestra recomendación - para que el mensaje de salida quede limpio, (es más engorroso borrar la parte no deseada). Por lo tanto se debe de citar y resumir 
sólo lo que se va a contestar. Al responder a un mensaje es conveniente marcar con un símbolo '>' los puntos a los que se está haciendo referencia para que el receptor lo recuerde, no incluyendo todo el artículo. Se borra lo que no se responda ya que sino se rompe el argumento de respuesta.

- En caso de respuesta a un mensaje de Lista, es necesario hacer mención explícita de: a quién se está contestando, sobre qué tema, y en que momento de la conversación. Téngase en cuenta que, algunas veces, la Red puede jugar malas pasadas y ocasionar retrasos en la entrega de mensajes, con lo que la secuencia temporal de recepción puede perderse; puede haber usuarios que reciban la respuesta antes que el mensaje inicial.

- 3.Si la contestación es personal, lo adecuado es enviar el mensaje de respuesta únicamente a la persona en cuestión. No se deben enviar mensajes personales a una Lista. Como regla general hay que evitar los diálogos "uno a uno", que pueden no interesar a la mayoría.

- Cuando se responda a cuestiones planteadas en la Lista se hará con hechos probados, indicando, a ser posible, fechas y situaciones, no con argumentos que se hayan oído de otros. Es muy común que los rumores crezcan como una bola de nieve, no debemos permitir que el correo electrónico nos sirva de "ladera" aceleradora.

- Antes de responder a un mensaje de Lista, es conveniente leer los que han llegado y todavía no se han abierto. En definitiva, debemos informarnos antes de que las consultas planteadas no hayan sido respondidas por más personas. Suele enojar ver una y otra vez una misma repuesta. Lo más probable es que las cuestiones sencillas hayan sido respondidas con anterioridad. 


\section{Participación en grupos de discusión, debate e información.}

Intente participar de forma adecuada en las Listas, no se limite a escuchar, sus opiniones también son interesantes. Es la mejor forma de enriquecer los debates. Es recomendable que permanezca una temporada leyendo los temas que se tratan en la Lista, (esté una temporada "escuchando"), para tener información de la orientación de la misma.

\section{Envío de archivos adjuntos.}

El envío de archivos adjuntos, pese a ser muy cómodo, tiene el inconveniente de los tamaños, que suelen bloquear la mayoría de las cuentas de correo, muy restringidas en cuanto a capacidad. Si su interlocutor dispone de facilidades FTP, es mejor usar este método. En caso contrario, asegúrese previamente de que el "adjunto" entrará sin dificultad y no bloqueará el espacio reservado para la cuenta de correo. Para las listas, intente en lo posible no enviar documentos, figuras o mensajes adjuntos. No decimos que esté prohibido.

\section{Publicidad.}

No se debe utilizar una Lista para enviar publicidad o ventas de un producto de la que se saque un beneficio económico, directa o indirectamente. Estas técnicas son mal vistas por los suscriptores de las listas de discusión. Sin embargo, existen suscripciones a Listas y cuentas de correo privadas que avisan de la posibilidad de recibir este tipo de mensajes. Éstos son, precisamente, aquellos mensajes que se califican como no solicitados y no los que distribuyen normalmente información de actividades culturales, sindicales, profesionales, etc, que interesan a la mayoría de los miembros de una Lista. 


\section{Se deben usar títulos descriptivos para los mensajes.}

Es muy conveniente poner un tema bien claro, corto, explícito y pertinente en el campo "Subject:" de la cabecera del mensaje, tanto si se trata de una Lista como de mensajes individuales o restringidos a una serie de destinatarios. Ello facilita su selección para su lectura ordenada, por orden de prioridades o urgencia. Los miembros de una Lista tienen intereses muy diferentes, así les damos la posibilidad de no abrir los mensajes no deseados. En otras palabras la línea "Subject" de un mensaje debe de ser lo suficientemente limitada y descriptiva como para que el receptor no pierda tiempo en decidir si lo lee o no.

\section{Cuidado con el humor y sarcasmo.}

Si el idioma del mensaje no es el nativo, pueden ser mal interpretadas las palabras. Hay que asegurarse de que las expresiones divertidas no sean entendidas de forma errónea. La red tiene desarrollados unos símbolos para apoyar el significado de las palabras, los emoticones, que deben ser usados en caso de duda (ejemplo: ":-)" quiere decir algo gracioso o ";-)" algo pícaro etc.). A este respecto les recomendamos que lean los artículos aparecidos en esta misma sección, "CIBERMANERAS", en los números cuatro y cinco de Vivat Academia".

\section{Se debe hacer partícipes a los demás de los hallazgos.}

Cuando se solícita información de alguien de un grupo y las respuestas se reciben de forma privada, es un gesto de cortesía proporcionar dichas repuestas a las demás personas de ese grupo. La mejor forma de hacerlo es reunir todas las respuestas en un artículo y enviarlo al grupo.

\section{Sobre la apropiación de ideas.}


En los casos en los que se usen comentarios, ideas o material de otras personas o publicaciones para enviarlos, sea a un interlocutor privado, sea a una Lista, se deben hacer explícitas la procedencia y el autor. Es malo para todos que el destinatario termine por asignarle la autoría al remitente.

\section{Sobre la privacidad.}

Cuando se envía algo por la red, se debe tener en cuenta que la información es de dominio público. Hay que ser consciente del efecto que puede causar la circulación de información o material que está restringido al ámbito del centro, grupo, institución o empresa.

\section{Firmas.}

Aunque el destinatario recibe la dirección "e-mail" del remitente como información del origen de los mensajes, es conveniente firmarlos. Las firmas deberán ser cortas. El principal objetivo de las mismas es ayudar a las personas que componen la red a poderse localizar en ésta. Cada firma incluirá por lo menos la dirección electrónica y la dirección postal.

\section{Uso de siglas.}

En el caso de utilizar siglas de instituciones, grupos, empresas, etc, es conveniente tener la amabilidad de explicar su significado en la primera aparición.

15. Criterios de cientificidad en las listas de distribución. 
Cuando se pertenece a una Lista de distribución, las participaciones conviene que se atengan a las siguientes reglas:

1. Ser todo lo crítico que se pueda con uno mismo antes de enviar una aportación.

a) Hacer el máximo esfuerzo por detectar errores.

b) Buscar contraargumentos y contraejemplos en las respuestas.

c) Evaluar su interés general.

d) Constatar que tiene una calidad similar o superior a la mayoría de las aportaciones.

2. Acompañar las afirmaciones que se realicen de su correspondiente explicación y, en su caso, de su breve descripción e incluso, a ser posible, predicción contrastable. No hacer afirmaciones vacías de contenido o meros enunciados de ideas. Todo lo que se escribe tiene que estar argumentado.

3. Precisar las fuentes de las informaciones como si se tratase de una publicación científica. Al referirse a libros, revistas, direcciones Web, etc, deben proporcionarse los suficientes datos como para que cualquier lector pueda acceder directamente a ellos y constatarlos por sí mismo.

4. Ser altamente crítico con los mensajes de los demás y buscar permanentemente la mejorara de sus contenidos. Esto debe hacerse con un lenguaje sumamente respetuoso, nunca hiriente ni descalificador. Se asume que la imperfección y el error es la situación normal. Los que participan tienen que considerar que una crítica bien fundada es un gran regalo intelectual, por lo que han de estar agradecidos a quién se la realiza. 
Cumplir con estas cuatro reglas mínimas de rigor científico puede parecer al principio algo complicado, pero tras un cierto entrenamiento es posible escribir mensajes con fluidez y rapidez.

\section{El correo no solicitado.}

Sobre la definición de correo no solicitado hay cierta polémica, por cuanto, en comparación con el correo ordinario donde la mayoría de las cartas recibidas no son solicitadas, - incluidas las de Hacienda" :-) -, en el correo electrónico las cosas cambian un poco debido a que el usuario de una cuenta privada, por la que tiene que abonar cierta cantidad, corre con parte de los gastos de la recepción. Así, el ejemplo que se pone como tipificador del correo no solicitado es :"aquél en que el anunciante descarga en transmisores y destinatarios el coste total o parcial de sus operaciones publicitarias, tanto si quiere como si no".

Normalmente se distinguen dos tipos de correo no solicitado definidos por las siglas UBE (del inglés: unsolicited bulk email, correo) y UCE (también del inglés: unsolicited commercial email). En ambos casos el coste es para el destinatario y la información transmitida es ajena a las actividades normales de la lista a que se envía. Para hacerse una idea de la limitación del concepto "no solicitado", diremos algo que es muy conocido de aquellos que tienen abiertas cuentas de correo en los distribuidores gratuitos: es bastante común recibir en este tipo de servidores información masiva publicitaria de todo tipo de actividades, incluidas las pornográficas.

Naturalmente, dentro de una empresa o institución, el envío de información a todos los que poseen cuenta en sus propios servidores, relativa a las actividades desarrolladas en su seno, no se considera correo no solicitado. Esa es la mejor forma 
de evitar el uso del papel, caro, y los servicios internos del correo ordinario. Sin embargo, dado que la información es "poder", muchas empresas ven con malos ojos que se difundan noticias entre sus miembros, sin haber sido controladas por sus directivas, no dudando en calificar de UBE los mensajes correspondientes.

Resumiendo, es recomendable no usar el envío masivo a los miembros de una lista, cuando los mensajes hacen referencia a informaciones alejadas de las actividades propias de su entorno.

\section{El problema del SPAM.}

Literalmente "spam" significa carne enlatada, sobre todo de cerdo, haciendo alusión a que es de la peor calidad. Sin embargo, el origen del término en el argot del correo electrónico se debe a una escena de Monty Python, que tiene lugar en una cafetería de unos estudios de televisión. Durante su desarrollo la palabra "spam" aparece en el menú ofrecida como una posible elección del mismo, hasta que el único diálogo posible es "spam, spam, spam, spam, spam..."

Esto sucede cuando se envían masivos mensajes electrónicos, indiscriminadamente, que sugieren a su vez el envío, por parte del receptor, de nuevos mensajes, a un gran número de destinatarios nuevos o no, ya que el incauto no es consciente de quiénes, junto con él, son los receptores del correo inicial. Normalmente el remitente original es desconocido, ya que utiliza trucos para mantener anónima su identidad. Esto provoca el colapso de cuentas y servidores de correo, que es lo que en realidad pretende el autor. Suelen hacer llamadas a los derechos humanos, a la posibilidad de salvar una vida, etc. Es muy fácil caer en la trampa, sobre todo cuando se es novato en el uso del correo electrónico; y son de difícil detección, ya que, al cabo del primer ciclo de circulación, el destinatario lo recibe de algún conocido o compañero, que ha sido engañado,y del que no puede sospechar malas intenciones. 
La mejor recomendación es abstenerse de reenviar mensajes que soliciten la difusión masiva a todas las direcciones que uno posee.

En este aspecto hay algo de confusión, ya que algunos administradores de correo califican de "spam, el envío de gran número de mensajes, hablando de "mensajes encadenados" para designar lo comentado anteriormente. La clave está en el adverbio "indiscriminadamente", es decir a destinatarios completamente ajenos al texto del mensaje; en caso contrario sería también "spam" la distribución de correo a una lista, lo que resulta absurdo. Es más, en las definiciones encontradas en Internet, se hace especial énfasis en el hecho de que los mensajes "spam" son generadores de otros nuevos.

\section{El problema de los mensajes BOMBA.}

Aunque no hace falta recomendar a nuestros lectores la abstención de este tipo actividad, si conviene conocer en qué consiste. El término en el argot informático, como es natural de origen inglés, es "mail bombing". Todo consiste en dirigir gran número de mensajes a un usuario, servidor o lista, varias veces por segundo, con el objeto de paralizar el servicio por saturación de las líneas, de la capacidad de CPU del servidor, o del espacio en disco del servidor y/o usuario. En español también son llamados mensajes de saturación.

Una versión diferente, pero igualmente destructiva, de los mensajes BOMBA, consiste en suscribir, automáticamente, a la víctima a miles de listas de correo. Dado que en este caso los ataques provienen de varias direcciones, son mucho más difíciles de atajar.

\section{Difusión de contenido inadecuado.}


Resulta evidente que no se deben enviar mensajes de contenido ilegal por naturaleza (todo aquello que constituya complicidad con hechos delictivos). Los ejemplos característicos son: apología del terrorismo, programas piratas, pornografía infantil, amenazas, estafas, esquemas de enriquecimiento piramidal, virus o códigos hostiles, etc.

Tampoco se deben enviar mensajes a una Lista temática fuera del contenido normal de la misma. En esos casos la Lista suele disponer de un moderador que filtra los contenidos inadmisibles.

\section{Difusión a través de canales no autorizados.}

Este punto hace referencia al uso no autorizado de una estafeta ajena para reenviar correo propio. Aunque el mensaje en sí sea legítimo, se están utilizando recursos ajenos sin su consentimiento. Aquí normalmente no se pone ninguna objeción cuando la estafeta es de uso público y ha sido declarada como tal.

\section{Recomedación final.}

A fin de no perder información, sobre todo en aquellos servidores que limitan la disponibilidad de capacidad y el tiempo de disponibilidad de los mensajes en su seno, es recomendable abrir con frecuencia el buzón de correo (la mayoría de los programas avisan de la llegada del mismo), cuidando de no tener activada la opción "guardar los mensajes en el servidor". De esta forma la información se almacenará en su ordenador, liberando espacio para la llegada de nuevo correo.

Nota: (Estas normas están inspiradas en la normativa que para grupos de discusión y listas de distribución ha establecido la RedIris). 